\title{
Práticas integrativas e complementares na odontologia: a percepção dos indivíduos
}

\section{atendidos}

\author{
Integrative and complementary practices in dentistry: the perception of the attended individuals
}

Prácticas integradoras y complementarias en odontología: la percepción de las personas atendidas

Recebido: 19/08/2021 | Revisado: 23/08/2021 | Aceito: 26/08/2021 | Publicado: 29/08/2021

\author{
Rachel Ivo de Figueiredo \\ ORCID: https://orcid.org/0000-0002-1531-0306 \\ Universidade Federal de Minas Gerais, Brasil \\ E-mail: rachelivof@hotmail.com \\ Janice Simpson de Paula \\ ORCID: https://orcid.org/0000-0002-5396-0959 \\ Universidade Federal de Minas Gerais, Brasil \\ E-mail: janicesimpsondp@yahoo.com.br \\ Rafaela Reis da Silva \\ ORCID: https://orcid.org/0000-0001-6435-9942 \\ Universidade Federal de Minas Gerais, Brasil \\ E-mail: rafelareissilva@gmail.com \\ Rosa Núbia Vieira de Moura \\ ORCID: https://orcid.org/0000-0002-8947-2797 \\ Universidade Federal de Minas Gerais, Brasil \\ E-mail: nubiamoura@ufmg.br
}

\begin{abstract}
Resumo
O objetivo do estudo foi compreender a percepção dos pacientes atendidos no Projeto de Extensão "Práticas Integrativas Complementares em Saúde: Acupuntura em Odontologia", da Faculdade de Odontologia da Universidade Federal de Minas Gerais, quanto ao resultado do tratamento pelas Práticas Integrativas Complementares em SaúdePICS. Trata-se de pesquisa qualitativa, com população de estudo escolhida por conveniência, composta por pacientes atendidos no Projeto de Extensão referido, no ano de 2019. Para a obtenção das falas, empregou-se a estratégia do grupo focal, que foi iniciado pela Pergunta Norteadora: "O que foi para você ser atendido nesse Projeto da FAO com as PICS?". A interpretação das falas dos pacientes foi conduzida pela análise de conteúdo, com base na fenomenologia. Após a análise, emergiram seis temas principais: Conhecimento prévio sobre PICS; Queixa Principal (QP); Impacto do atendimento nas dimensões biopsicossociais; Técnicas utilizadas no projeto; Percepção quanto à efetividade das PICS e a Busca da solução da QP anteriores ao projeto. Concluiu-se que os participantes, mesmo com reduzido conhecimento sobre terapias complementares, explicitaram a importância e a efetividade do Projeto de Extensão, a partir da percepção dos resultados positivos sentidos com o tratamento pelas PICS.

Palavras-chave: Terapias complementares; Acupuntura; Odontologia; Dor facial.
\end{abstract}

\begin{abstract}
The aim of the study was to understand the perception of patients attended in the Extension Project "Complementary Integrative Practices in Health: Acupuncture in Dentistry", from the Faculty of Dentistry of the Federal University of Minas Gerais, regarding the outcome of treatment by Integrative Complementary Practices in Health. This is a qualitative research, with a study population was chosen for convenience, composed of patients assisted in the aforementioned Extension Project, in 2019. To obtain the data, the focus group strategy was used, which was initiated by the Question Advisor: "What was it like for you to be assisted in this Project of the Faculty of Dentistry of UFMG with the complementaty therapies?". The interpretation of the patients' statements was conducted through content analysis, based on phenomenology. After the analysis, six main themes emerged: Prior knowledge of PICS; Main Complaint; Impact of care on biopsychosocial dimensions; Techniques used in the project; Perception of the effectiveness of the complementaty therapies and the search for the main complaint solution prior to the project. It was concluded that the participants, even with little knowledge about complementary therapies, explained the importance and effectiveness of the Extension Project, based on the perception of the positive results felt with the treatment by the complementaty therapies.
\end{abstract}

Keywords: Complementary therapies; Acupuncture; Dentistry; Facial pain.

\section{Resumen}

El objetivo del estudio fue conocer la percepción de los pacientes atendidos en el Proyecto de Extensión "Prácticas Integradoras Complementarias en Salud: Acupuntura en Odontología", de la Facultad de Odontología de la 
Universidad Federal de Minas Gerais, sobre el resultado del tratamiento por Prácticas Integradoras Complementarias en Salud. Se trata de una investigación cualitativa, con una población de estudio elegida por conveniencia, compuesta por pacientes atendidos en el citado Proyecto de Extensión, en 2019. Para la obtención de los datos se utilizó la estrategia de grupo focal, la cual fue iniciada por el Asesor de Cuestiones: “¿Cómo fue para ti ser atendido en este proyecto de la Facultad de Odontología de la UFMG con las terapias complementarias?" La interpretación de las declaraciones de los pacientes se realizó mediante análisis de contenido, basado en la fenomenología. Tras el análisis, surgieron seis temas principales: Conocimientos previos de terapias complementarias; Queja principal; Impacto del cuidado en las dimensiones biopsicosociales; Técnicas utilizadas en el proyecto; Percepción de la efectividad de las terapias complementarias y búsqueda de la solución de las quejas principales previamente al proyecto. Se concluyó que los participantes, aún con poco conocimiento sobre terapias complementarias, explicaron la importancia y efectividad del Proyecto de Extensión, a partir de la percepción de los resultados positivos que sentían con el tratamiento por parte de las terapias complementarias.

Palabras clave: Terapias complementarias; Acupuntura; Odontología; Dolor facial.

\section{Introdução}

A odontologia, assim como o campo da saúde ocidental como um todo, atualmente entende o processo saúde-doença principalmente como o modelo biomédico, de forma tecnicista e objetiva. Dessa forma, há uma valorização excessiva da tecnologia, ao mesmo tempo em que há uma desqualificação do senso comum e uma generalização da saúde, negligenciando a concepção individual de saúde, bem estar, contexto e condição de cada pessoa. Assim, faz-se necessário a articulação do modelo atual com a humanização do cuidado, em que consiste na escuta e no respeito pelas singularidades e característica socioculturais de cada realidade (Gomes, et al., 2008).

A Organização Mundial da Saúde (OMS) vem, nos últimos anos, reconhecendo a importância das práticas integrativas e complementares e incentivando o uso dessas medicinas em todo o mundo (WHO, 2013). Seguindo essa linha de pensamento, o uso Acupuntura vem sendo fomentado no Brasil pela Política Nacional de Práticas Integrativas e Complementares (PNPIC), que incentiva a inserção dessas práticas no Sistema Único de Saúde (Brasil, 2015). Sendo assim, o Conselho Federal de Odontologia (CFO) reconheceu, em 2015, a Acupuntura como especialidade odontológica, com o objetivo de ser utilizada para tratamento, prevenção e manutenção do estado geral de a saúde do paciente odontológico, quando houverem situações clínicas que envolvam estruturas do sistema estomatognático e assim, respeitando a área de atuação do cirurgião dentista.

A acupuntura visa o tratamento e a cura de agravos pela aplicação de estímulos através da pele nos chamados pontos de acupuntura, em que há relação íntima com nervos, vasos sanguíneos, tendões e cápsulas articulares. Assim, há o reestabelecimento do fluxo e do equilíbrio energético do paciente, e a consequente recuperação da função motora, redução da dor e relaxamento (Rando-Meirelles, et al., 2009). Além disso, foi descrito na literatura a eficácia da acupuntura para dores orofaciais e tinido, em que após duas sessões foi possível observar melhora dos sintomas, sendo que eles deixaram de existir após seis sessões, por meio do relaxamento da musculatura da cabeça e pescoço (Vera, et al., 2013). Além disso, estudos também relatam casos em que tal técnica apresentou resultados positivos no tratamento de DTM (disfunção temporomandibular), xerostomia, bruxismo e na diminuição de consumo de medicamentos pelos efeitos analgésicos e antiinflamatórios (Vianna, et al., 2008).

Também é importante ressaltar a eficácia da Acupuntura e da Medicina Chinesa como um todo em relação aos seus efeitos sistêmicos. De acordo com o estudo realizado por Cintra e Figueiredo (2010), as pessoas entrevistadas relataram alterações em seu estado emocional e/ou psicológico ou comportamental, além de mudanças no seu cotidiano, como atividades físicas e alimentação. Também houve o relato de controle da dor e melhora da autoestima, além de retrocesso de diversas patologias pelo tratamento com Acupuntura.

Nesse estudo objetivou-se compreender a percepção dos pacientes atendidos no Projeto de Extensão Práticas Integrativas Complementares em Saúde: Acupuntura em Odontologia, da Faculdade de Odontologia da Universidade Federal de Minas Gerais (UFMG), nos anos de 2019 e 2020, quanto ao resultado com o tratamento pelas técnicas das PICS. 


\section{Metodologia}

Estudo de natureza qualitativa, teve por interesse compreender a percepção dos pacientes atendidos no Projeto de Extensão "Práticas Integrativas e Complementares em Saúde: Acupuntura na Odontologia", no ano de 2019 e 2020, com relação ao resultado do tratamento. O método qualitativo de pesquisa ocupa do nível relacional e subjetivo da realidade social por meio da história, das vivências, dos valores, das crenças e das atitudes dos atores sociais, por meio de uma riqueza de detalhes e conteúdos (Minayo, 2012). Várias são as técnicas para produção de achados qualitativos, dentre as quais o grupo focal tem o propósito de promover uma discussão participativa de um tema específico (Trad, 2009).

No projeto são empregadas técnicas apoiadas na Medicina Tradicional Chinesa, como a Acupuntura, a Auriculoacupuntura, a Eletroacupuntura, a Môxabustão, dentre outras possibilidades. Os atendimentos são realizados por voluntários e professores especialistas na área, acompanhados por alunos da graduação e pós-graduação vinculados ao projeto, em local fixo (Sala 2118: Prótese Buco-Maxilo-Facial) na Faculdade de Odontologia da Universidade Federal de Minas Gerais, bem como, de forma itinerante pelas clínicas da Faculdade, de acordo com a demanda/indicação/solicitação de outros professores das clínicas mediante de agendamento prévio.

Os pacientes que aportam no Projeto vêm encaminhados de outras clínicas e projetos de extensão da Faculdade e instituições parceiras, para tratamento de diversas patologias que possuem base nas evidências científicas existentes sobre uso da Acupuntura na Odontologia e as recomendações da Organização Mundial da Saúde. Assim, são recebidos pacientes com dor aguda e crônica, xerostomia, bruxismo, dor decorrente de tratamento ortodôntico, neuralgia do trigêmeo, dor orofacial entre outros.

A coleta de dados se deu por meio de um grupo focal (GF) realizado em abril de 2021. Todos os 29 pacientes do projeto foram contactados, via telefone e, na sequência, enviado um convite com proposta de datas e horários, bem como o Termo de Consentimento Livre e Esclarecido-TCLE para assinatura. Houve retorno de cinco pacientes que compuseram a amostra. No planejamento, foi definida a seguinte pergunta norteadora: "O que foi para você ser atendido nesse Projeto da FAO com as PICS?". Estabeleceu-se um roteiro para discussão, mostrado abaixo, que deveria abordar, até a saturação, questões como:

- $\quad$ Conhecimento das técnicas que foram utilizadas durante o tratamento e quais;

- $\quad$ Conhecimento de alguma outra prática entre as PICS e quais;

- $\quad$ O que levou a busca pelo Projeto;

- Tratamentos anteriores ao Projeto para a queixa principal;

- Técnicas usadas durante o tratamento no Projeto;

- $\quad$ Melhora da queixa principal pelas PICS;

- $\quad$ Satisfação com resultado do tratamento.

O GF foi conduzido pelas pesquisadoras deste estudo, ambas participantes do projeto, uma aluna voluntária como observadora e a Professora Orientadora como facilitadora. A reunião foi realizada na Plataforma Microsoft Teams®, gravada na íntegra e salva para posterior análise. A facilitadora tinha como funções incentivar a participação de todos, evitar o predomínio de um participante sobre os outros e manter a discussão nos limites dos tópicos de interesses, até o momento em que não surgissem novas falas com conteúdo pertinente ao objetivo do estudo, sem fazer quaisquer julgamentos.

A duração da reunião foi de 01 hora e 40 minutos e os participantes foram informados no início da reunião sobre intuito e o formato da discussão, sobre o caráter informal da reunião e a necessidade da participação de todos, sendo que ela foi feita em ambiente de harmonia, apropriado às finalidades propostas.

Após a realização do grupo focal, foi feita a transcrição das falas sem a identificação dos pacientes e as respostas 
obtidas foram organizadas em planilha Excel criada para o estudo, utilizando-se códigos de identificação, por exemplo P1, P2. O material transcrito foi submetido a leituras exaustivas para uma compreensão mais aperfeiçoada. Os achados foram analisados segundo a análise de conteúdo, proposta por Graneheim \& Lundman (2004). Seguindo a orientação metodológica, foram identificados, no texto, as unidades de significados representadas nas falas. De cada unidade de significado foi extraído a sua essência, obtendo-se a unidade de significado condensada. Em seguida, realizada a interpretação, criando-se com isso as categorias de análise, posteriormente agrupadas em temas. Esse processo pode ser visto no Quadro 1. As falas foram agrupadas em seis temas, sendo eles: Conhecimento prévio sobre as PICS, Queixa Principal (QP), Impacto nas dimensões biopsicossociais, Técnicas utilizadas, Percepção quanto à efetividade das PICS e Busca da solução da QP até chegar ao Projeto.

O projeto foi aprovado no Comitê de Ética em Pesquisa da Universidade Federal de Minas, segundo o Parecer Consubstanciado n. 2.892.995 e registrado pelo CAAE: 78789317.9.0000.5149.

Quadro 1 - Exemplo de etapas da análise de conteúdo deste estudo, segundo Graneheim e Lundman (2004).

\begin{tabular}{|c|c|c|c|c|}
\hline Unidade de significado & $\begin{array}{l}\text { Unidade de significado } \\
\text { condensado }\end{array}$ & $\begin{array}{c}\text { Unidade de } \\
\text { significado } \\
\text { (Interpretação) }\end{array}$ & $\begin{array}{c}\text { Subtema } \\
\text { (Categorias) }\end{array}$ & Tema \\
\hline $\begin{array}{l}\text { Eu não conhecia, eu não sabia nada de } \\
\text { acupuntura [...] Só via em filme. E aí a } \\
\text { acupuntura assim, era um pouco surreal [...] } \\
\text { vou colocar uma agulha lá no pé prá } \\
\text { melhorar, sei lá, DTM, como assim né, a } \\
\text { agulha não vai ser aqui no meu trapézio, no } \\
\text { masseter. }\end{array}$ & $\begin{array}{l}\text { Eu não conhecia, eu não sabia } \\
\text { nada de acupuntura [...]. }\end{array}$ & $\begin{array}{l}\text { Buscando caminhos } \\
\text { para a melhora }\end{array}$ & $\begin{array}{l}\text { Sem contato } \\
\text { prévio com as } \\
\text { PICS }\end{array}$ & $\begin{array}{l}\text { Conhecimento } \\
\text { prévio sobre } \\
\text { PICS }\end{array}$ \\
\hline $\begin{array}{l}\text {..eu tinha muitas crises de DTM e de } \\
\text { enxaqueca - hoje que sei que é enxaqueca, } \\
\text { né, naquela época eu não sabia que era } \\
\text { também enxaqueca... }\end{array}$ & $\begin{array}{l}\text {...eu tinha muitas crises de } \\
\text { DTM e de enxaqueca... }\end{array}$ & Dores constantes & $\begin{array}{c}\text { Queixa } \\
\text { Principal (QP) }\end{array}$ & $\begin{array}{l}\text { Queixa Principal } \\
\text { (QP) }\end{array}$ \\
\hline $\begin{array}{l}\text {...assim, é isso que eu falo, porque eu tava } \\
\text { num momento de muito estresse e... tirar a } \\
\text { dor, te relaxa, então melhora o sono, } \\
\text { melhora o emocional, melhora tudo. }\end{array}$ & $\begin{array}{l}\{\ldots \text {...eu tava num momento de } \\
\text { muito estresse e tirar a dor, te } \\
\text { relaxa, melhora o sono, melhora } \\
\text { o emocional, melhora tudo. }\end{array}$ & $\begin{array}{l}\text { PICS na melhora da } \\
\text { Saúde sistêmica }\end{array}$ & $\begin{array}{l}\text { Qualidade de } \\
\text { vida }\end{array}$ & $\begin{array}{l}\text { Impacto nas } \\
\text { dimensões } \\
\text { biopsicossociais }\end{array}$ \\
\hline $\begin{array}{l}\text { Fiz ventosa, fiz auriculoterapia, fiz } \\
\text { acupuntura, fiz reiki, um pouco de } \\
\text { aromaterapia com aquele... eu não lembro, } \\
\text { aquele sachê que vocês colocam assim no } \\
\text { nosso rosto... }\end{array}$ & $\begin{array}{l}\text { Fiz ventosa, auriculoterapia, } \\
\text { acupuntura, reiki, um pouco de } \\
\text { aromaterapia, } \quad \text {...aquele } \\
\text { sachê...no nosso rosto... }\end{array}$ & $\begin{array}{l}\text { Diversidade de } \\
\text { técnicas disponíveis }\end{array}$ & $\begin{array}{l}\text { Recursos } \\
\text { terapêuticos em } \\
\text { PICS }\end{array}$ & $\begin{array}{l}\text { Técnicas } \\
\text { utilizadas }\end{array}$ \\
\hline $\begin{array}{l}\text { Mas assim, pra mim foi uma experiência } \\
\text { quase que libertadora porque libertar da dor } \\
e ́ \text { algo incrível e só quem tá numa fase } \\
\text { aguda de um processo doloroso, de um } \\
\text { processo que gera uma inflamação } \\
\text { muscular, sabe o quanto isso é libertador... }\end{array}$ & $\begin{array}{l}\{\ldots \text { pra mim foi uma experiência } \\
\text { libertadora... }\}\end{array}$ & $\begin{array}{l}\text { Promoção de } \\
\text { analgesia, melhora } \\
\text { do sono, redução do } \\
\text { estresse, aumento } \\
\text { do relaxamento, } \\
\text { melhora do } \\
\text { emocional. }\end{array}$ & $\begin{array}{l}\text { Melhora da QP } \\
\text { e dos sintomas } \\
\text { correlatos }\end{array}$ & $\begin{array}{l}\text { Percepção } \\
\text { quanto à } \\
\text { efetividade das } \\
\text { PICS }\end{array}$ \\
\hline $\begin{array}{l}\text {... eu também sempre fui uma pessoa meio } \\
\text { cética, assim sabe, porque eu falava assim, } \\
\text { não, tá, pode ser que melhore, vamos lá, eu } \\
\text { passei esse tempo todo usando placa, não } \\
\text { resolve, toma remédio, não resolve, não sei }\end{array}$ & $\begin{array}{l}\text { \{...sempre fui uma pessoa meio } \\
\text { cética, pode ser que melhore, eu } \\
\text { passei esse tempo todo usando } \\
\text { placa, toma remédio, não } \\
\text { resolve...\} \{...O que me falarem }\end{array}$ & $\begin{array}{l}\text { Busca pelas PICS } \\
\text { por pacientes com } \\
\text { casos crônicos de } \\
\text { saúde, como a dor. }\end{array}$ & $\begin{array}{l}\text { Falta de } \\
\text { efetividade da } \\
\text { terapêutica } \\
\text { tradicional. }\end{array}$ & $\begin{array}{lr}\text { Busca da } & \text { da } \\
\text { solução da } & \text { QP } \\
\text { até chegar ao } \\
\text { Projeto. }\end{array}$ \\
\hline
\end{tabular}


o que. $O$ que me falarem, se me falar que pular na piscina vai resolver eu tava indo, qualquer coisa pra poder para a dor.

\section{eu tava indo, qualquer coisa prá}

poder parar a dor.

Fonte: Dados da pesquisa (2018).

\section{Resultados e Discussão}

Ao ler as narrativas, depreendeu-se que os participantes tinham pouco conhecimento prévio sobre as PICS. A percepção está relacionada às dores crônicas, por isso, procuraram os tratamentos complementares para ajudar no controle da dor. Zhang et al., 2015 destaca que, o conhecimento prévio dos pacientes sobre as PICS e a procura por elas se dá, majoritariamente, por pessoas que sofrem de condições crônicas como a dor. Além disso, pacientes com dor orofacial, em geral, parecem não estar satisfeitos com o atendimento baseado no modelo biomédico e procuram outros métodos de tratamento (Chagas, et al., 2021). Os achados deste estudo concordam com esse fato, visto que os pacientes não tinham grande conhecimento prévio sobre as PICS, mas sofriam de dores crônicas e por isso procuraram tratamentos complementares para ajudar a controlar a dor. A exemplo disso, seguem as falas:

P1: Eu não conhecia, eu não sabia nada de acupuntura [...]E aí a acupuntura assim, era um pouco surreal [...] vou colocar uma agulha lá no pé prá melhorar, sei lá, DTM, como assim né, a agulha não vai ser aqui no meu trapézio, no masseter.

P2: Eu conheço porquê... Só conhecia também, nunca tive, nunca busquei fazer... Mas porque o meu irmão, ele tem um problema de visão, e ele foi, (há) muitos anos atrás, ele foi fazer um tratamento em Cuba e lá eles usavam.

P3: E eu, assim, não tinha conhecimento nenhum sobre as PICS, sabia que existia acupuntura por alto, tipo assim, sei que existe, eu tenho uma prima que já tinha feito pra dores no corpo e ela já tinha me falado que era bom, mas eu confesso que eu não, nunca tinha pensado em associar às dores vindas de uma DTM. Eu achava que a acupuntura era pra algo mais geral, tipo assim, ah eu vou fazer e vai me dar um bem estar geral. Eu não tinha esse conhecimento que eu poderia direcionar para um problema específico.

P4: Olha, eu não tinha conhecimento, igual as meninas falaram, tipo assim, sabia que existia, mas eu não sabia como, onde e porque, então não tinha conhecimento nenhum.

P5: Então, a gente não tinha conhecimento nenhum sobre o que que era assim. E na minha vida assim, eu sabia que existia acupuntura, sabia que existia aurículo, já tinha ouvido falar de reiki, assim...

As principais queixas relatadas foram: dores faciais advindas da DTM, bruxismo, estresse e ansiedade. Nesse contexto, deve-se levar em conta o viés do Projeto, que propõe tratar condições associadas à odontologia e por isso, a maior parte dos pacientes atendidos apresentou o mesmo tipo de queixa principal. De acordo com Boscaine et al., (2019), a acupuntura é eficaz nos tratamentos de dores faciais em pacientes com DTM e é uma ótima escolha para controle dessas dores, por ter baixo índice de efeitos colaterais e possibilidade de uso contínuo (Garbelotti, 2016). Em relação ao estresse e ansiedade, a acupuntura tem se mostrado bastante eficaz em casos de problemas musculares com envolvimento emocional, visto que os trata de uma forma diferenciada, podendo levar a uma melhora na qualidade de vida do paciente e gerar maior autoconfiança (Florian, 2012). Considerando-se essas informações, seguem as falas: 
P1: [...] ]eu tinha muitas crises de DTM e de enxaqueca - hoje, que sei que é enxaqueca, né, naquela época eu não sabia que era também enxaqueca [...]eu tenho dores e crises fortes de DTM há mais de 10 anos[...] hoje em dia a própria dor é que tá te causando ansiedade.

P2: Eu, a princípio, fui lá por causa do bruxismo né, apertava demais, sentia muita dor de cabeça...

P3: ...quando eu comecei a ter muita, muita, muita dor que eu falei assim nossa, eu preciso de alguma coisa.

P4: Então, quanto mais estressada eu ficava, quanto mais ansiosa, mais pilhada que eu tava, mais dor eu sentia. Então tinha dia que eu acordava com tanta dor, e doía os dois lados, com tanta dor que minha boca travava e eu não conseguia destravar. E aquilo ali me gerava tanto estresse que eu passava o dia chorando, e quanto mais eu chorava, mais dor eu sentia. Aí juntava com a dor de cabeça, com a dor do músculo e aí virava aquela bola de neve.

Em relação ao impacto das PICS nas dimensões biopsicossociais, observa-se que as PICS proporcionam o aumento da qualidade de vida dos pacientes (Florian, et al., 2012) e diminuição do estresse e da ansiedade, de acordo com Santos et al., (2011). Além disso, a acupuntura oferece criação de vínculo terapêutico por meio de escuta acolhedora e promoção global do cuidado humano (Brasil, 2015). Segundo Vianna et al., (2008), a Acupuntura pode promover a diminuição do uso de medicamentos alopáticos por meio da redução da dor. Esses aspectos podem ser observados nas falas:

P1: Eu fui muito bem recebida no projeto[...]me ajudou a controlar um pouco as dores né[...] aí, as meninas lá né, as alunas e as prof ${ }^{\prime}$ queridas, super receptivas, super dispostas a ajudar e toda vez que eu ia no projeto acabava que era essa sensação que a maioria falou aqui, de você se sentir cuidada, de sentir que tem alguém te ajudando[...] há algo que alivia a dor que não só ficar tomando medicação, fazendo fisioterapia...

P2: Fui, o atendimento foi sensacional, pessoal muito gente boa mesmo, muito atencioso, no final, no último dia até levei um bolo pra todo mundo, gostei muito mesmo [...] eu tomava remédio assim, umas três vezes por semana e aí logo no início, assim quando a gente foi mantendo a constância eu já diminuí bastante os remédios de dor de cabeça, muito mesmo[...] fui em 2019 e até hoje em dia assim, não sei se tem a ver ou não, eu consumo menos remédio de dor de cabeça sabe[...] Porque realmente desde o projeto, associado à terapia, as minhas dores de cabeça melhoraram muito mesmo, então hoje eu não sou mais acostumada a tomar remédio e nem a sentir essa dor.

P3: ...pra mim foi assim, sensacional a melhora que eu tive, porque eu realmente tava num período de não dormir a noite de tanto que eu apertava, de ter dor o tempo todo, um estresse constante [...] foi uma experiência quase que libertadora[... Jlibertar da dor é algo incrível e só quem tá numa fase aguda de um processo doloroso, de um processo que gera uma inflamação muscular, sabe o quanto isso é libertador[...] ]eu tava num momento de muito estresse e... tira a dor, te relaxa, então melhora o sono, melhora o emocional, melhora tudo[...]principalmente por ter fatores emocionais muito ligados a gente acaba tendo uma terapêutica, um tratamento de consequência né, e eu sinto [...]que acupuntura, ela não relaxa só o músculo, [...] você sai com aquela sensação que você tá inteira relaxada, parece que até sua mente relaxa um pouco, sua ansiedade, seu estresse. Então acaba que você tem um tratamento de consequência, que é a dor muscular, mas ajuda no fator causal.

P4: Eu senti muita diferença, tipo assim, ao ponto de ter dia que eu não tinha dor, tipo, zero, zero, zero dor, eu conseguia viver bem e tudo mais [...] foi incrível e a atenção também todo dia, é estranho né você chegar assim pra 
uma consulta e tipo, o profissional te perguntar como que você tá. Quem me atendia, acho que cada dia era uma pessoa diferente, mas não era uma coisa muito assim, como eu vou falar... biomédica, sabe? Tinha toda uma questão de preocupar como que você tava e como eu tava me sentindo. Pelo fato de eu fazer odonto, então eles sabiam como que tava minha carga horária, sabiam o quanto eu tava desesperando, tipo, primeiro período né? Teve toda uma atenção especial.

P5: ...todo mundo do projeto assim é extremamente acolhedor, todo mundo te trata assim, como se te conhecesse a 50 mil anos e vamo sentar aqui, vamo resolver seu problema e tudo [...] e foi a primeira vez em 6 anos que eu não tive nada de dor assim, depois acho que de umas 5 semanas assim fazendo, realmente eu parei de sentir dor e isso pra mim foi uma sensação muito estranha porque assim, você acostuma né, a conviver com a dor, você até esquece que ela tá ali e quando ela some você fala tipo assim, gente... não sei, tá faltando alguma coisa assim [...] mudou minha vida de verdade, porque saber que existe alguma coisa que pode resolver o meu problema 100\%.

Tendo em vista as técnicas utilizadas, foram citadas pelos pacientes a acupuntura, a auriculoacupuntura, a ventosaterapia, o reiki e a aromaterapia, sendo que todas elas foram bem aceitas pelos pacientes, por exceção da auriculoacupuntura por um paciente. A acupuntura utiliza agulhas ou sementes (auriculoaupuntura) em pontos específicos e atua liberando mediadores com ação analgésica, relaxante e antiinflamatória (Vianna, et al., 2008), sendo que a auriculoacupuntura como terapia adjuvante reduz sintomas de dor e DTM mais rapidamente e mais significativamente do que a terapia oclusal isolada (Ferreira, et al., 2015).

Já a utilização do reiki, caracterizado pela imposição das mãos para canalização da energia vital, visando promover o equilíbrio energético, necessário ao bem-estar físico e mental (Brasil, 2018), promoveu redução significativa na percepção e experiência de dor em pacientes que foram submetidos a extração de dentes inclusos em estudo de Wirth et al., (1993).

Em relação à ventosaterapia, ela se caracteriza como uma técnica terapêutica de origem oriental, que utiliza sucção dos canais de energia para estímulo dos pontos de acupuntura (Brasil, 2018). Segundo estudo de Wang et al., (2017) ela conseguiu reduzir significativamente a intensidade da dor em pacientes em relação ao grupo controle, além de ser um método promissor para tratamentos de dor (Moura, et al., 2019).

Por fim, a aromaterapia é uma prática terapêutica que utiliza as propriedades dos óleos essenciais para recuperar o equilíbrio e a harmonia do organismo visando à promoção da saúde física e mental (Brasil, 2018). Segundo estudo de Lyra et al., (2010), a aromaterapia foi capaz de reduzir significativamente os níveis de estresse e ansiedade dos alunos de graduação da área da saúde.

P1: Fiz ventosa, fiz auriculoterapia, fiz acupuntura, fiz reiki, um pouco de aromaterapia com aquele... eu não lembro, aquele sachê que vocês colocam assim no nosso rosto...

P2: Lá eu também fiz, eu fiz assim, só acupuntura né e a auriculo.

P3: Ventosa não sei se entra nas PICS ou não, mas ventosa eu amo, amo ventosa, mas é igual eu falei, é engraçado porque eu usava pras minhas dores, no ombro, nas costas, mas eu não achava que eu conseguiria aplicar nas minhas dores miofasciais mesma [...] agora, a auriculo, eu confesso que eu nunca consegui usar muito bem... oи eи esquecia, ou eu tinha que ignorar que as sementinhas tavam ali e aí não funciona, porque você tem que apertar, ou eu começava a apertar e eu ficava irritada e tirava.

P4: E eu fiz também auriculoterapia [...] mas a aromaterapia, a acupuntura, que foi o que eu fiz, a auriculoterapia realmente funcionaram e funcionam muito pra mim. 
Em relação à percepção dos pacientes quanto à efetividade do tratamento, foi possível perceber que a melhora do sono, da dor e da ansiedade foram os parâmetros os quais os pacientes mais notaram melhora. É possível concluir que a acupuntura tem se mostrado tão eficiente no controle de dores faciais quanto as terapias convencionais (Branco, et al., 2005) e além disso, ela também tem se mostrado bastante eficaz em casos de problemas musculares e neuríticos com ou sem envolvimento de origem emocional (Florian, et al., 2012). Segundo estudo de Takiguchi et al., (2008), a acupuntura mostrou-se eficaz na melhora da dor, sono e qualidade de vida nos dois grupos participantes do estudo.

P3: ...mas realmente pra mim fez muito efeito, principalmente a acupuntura, eu via assim uma melhora significativa, principalmente no meu sono. De tudo que melhorou, meu sono melhorou muito, porque quando eu comecei tinha vez que aqueles 20 minutos ali da clínica era o tempo que eu melhor dormia assim, dormia melhor naqueles 20 minutos do que eu dormia as vezes em 6 horas de sono a noite porque eu apertava muito.

P4: Eu sentia muita dor e eu acho que pra mim o diferencial do projeto foi porque eu já tinha tomado remédio, não adiantou, eu usava plaquinha e também não adiantava [...] ]eu acho que a parte do projeto, pegou assim, no ponto de tratar o meи emocional porque o bruxismo ali tava muito ligado a minha ansiedade, ao meu estresse, eu acho que a partir do momento que pegou nessa questão emocional, eu acho que foi o diferencial de tudo.

Também foi possível verificar quais tratamentos os pacientes buscaram para controle das suas queixas principais anteriormente ao Projeto, sendo que esses foram o uso de placa oclusal, medicamentos alopáticos para dor e relaxantes musculares, tratamento ortodôntico, fisioterapia, laserterapia e tratamento com psicólogo. De acordo com a revisão sistemática de SASSI et al., (2017), apesar do crescente número de pesquisas sobre os tratamentos para DTM, ainda não há consenso sobre qual o melhor deles e sobre ao real benefício de cada um. Sendo assim, a acupuntura tem obtido bons resultados em tratamentos para DTM, principalmente por atuar no fator estresse (Rando-Meirelles et al., 2009) e, sobretudo, quando associada ou como um complemento ao tratamento convencional (Vasconcelos et al., 2011).

P1: ...toda vez que eu ia lá, fazia ajuste oclusal, e aí eu comecei a ficar meio cismada com aquilo, eu falava gente, eu tô fazendo esse ajuste oclusal e continuo com dor, daqui a pouco não vai ter mais o que esse homem desgastar [...] aí lá pro quarto ano, fiz um tratamento com placa oclusal [...] e aí era mais ou menos o mesmo relato das meninas. Dormir com a placa é muito desconfortável né, em geral a placa, ela fica muito justa e acaba causando um desconforto nos dentes [...] E aí eu coloquei aparelho, fiquei 7 anos de aparelho [...] durante os 3 primeiros anos eu continuava tendo as mesmas dores, mesmo fazendo orto. Diminuiu um pouco no início, mas depois voltou. [...] E aí nessa época, acho que no primeiro ano eu tomei dorflex, aí quando eu tava no quarto ano da faculdade, três anos depois, eu comecei a fazer uso de Miosan. No início, Miosan era uma beleza... hoje, pro Miosan fazer efeito eu tenho que tomar uns 3 [...] e aí foi uma época que eu tava fazendo de tudo tipo, aí eu fui no psicólogo, fui no psiquiatra, comecei a fazer atividade física, tudo que vocês imaginarem eu tava fazendo [...] eu fiz fisioterapia, fiz de tudo gente, só faltava ir num pai de santo, porque o resto... rezava, minha mãe fez promessa, fez novena, sabe esse tipo de coisa?

P2: E foi isso, então assim, na época lá eu tava tomando remédio de dor. Ah, eu cheguei a ir num médico achando que era enxaqueca também, então esse médico, ele me passou Naproxeno pra tomar. Então eu não tomava relaxante muscular, eu tomava o Naproxeno. Então na época do projeto eu tomava Naproxeno assim, umas 3 ou 4 vezes na semana, sabe? 
P3: A plaquinha resolveu bem, porém igual eu falei eu cheguei num nível que eu vi de estresse tão grande que nada resolvia. E aí a plaquinha para mim se tornou um fator estressante, que eu colocava, à noite eu queria apertar, aí dói os dentes, dói tudo e aí eu ficava mais estressada, era como se eu estivesse lutando com a plaquinha o tempo todo [...] então assim eu particularmente só tinha tentado a plaquinha e eu tava tomando remédio assim, só que eu evitava, mas quando eu vi que tinha que tomar remédio com uma constância absurda, foi um momento que eu preocupei e que graças a Deus eu tive a felicidade de casar com o momento de começar as práticas na faculdade né.

P4: Aí eu fiz a placa, eu demorei muito a me acostumar com ela, porque quanto mais eu usava, mais eu sentia dor [...] tinha dia que eu tomava remédio, quando ficava muito, muito crítica a situação, mas não adiantava muito [...] e associei também com a terapia, tipo de psicólogo.

P5: de tratamento, eu já fiz ajuste oclusal, fiz ortodontia muitos e muitos anos, remédios assim, em crises, sempre tomava, Nimesulida, Miosan, o que tivesse [...] fiz muita laserterapia também, mas laserterapia também, realmente assim, ajuda, ajuda bastante, pra mim não chegou no nível do que a acupuntura fez pra mim assim, mas a laserterapia ajuda a segurar bastante [...] e placa oclusal né, placa oclusal é melhor amiga, não tem como.

\section{Conclusão}

Os pacientes atendidos não tinham conhecimento aprofundado sobre o tema PICS antes de fazerem parte do Projeto de Extensão, sendo que todos sabiam da existência das práticas, porém não tinham conhecimento sobre como funcionam ou para que servem. Além disso, as queixas principais de todos os pacientes eram semelhantes, sendo elas DTM, enxaqueca, bruxismo, dores de cabeça, apertamento, estresse e ansiedade, fato considerado como um viés do estudo considerando o escopo do Projeto de Extensão. As técnicas utilizadas pelo projeto nesses pacientes foram a acupuntura, auriculoterapia, ventosaterapia, aromaterapia e reiki e os métodos utilizados pelos pacientes para tratamento das suas queixas principais antes de ingressarem no projeto foram a placa oclusal, medicamentos alopáticos para dor e relaxantes musculares, tratamento ortodôntico, fisioterapia, laserterapia e tratamento com psicólogo. Observa-se que o projeto teve impacto positivo nas dimensões biopsicossociais, visto que obteve aumento da qualidade de vida dos pacientes por proporcionar diminuição da dor, do apertamento, do estresse e ansiedade e do uso de medicamentos alopáticos. Por fim, foi possível observar que a percepção dos pacientes em relação à efetividade dos tratamentos utilizados no projeto foi positiva, uma vez que eles constataram melhora em seu sono, ansiedade e dor. Verifica-se então, que as PICS apresentaram êxito no tratamento das queixas principais relatadas pelos pacientes do estudo.

Considerando-se a demanda no Sistema Único de Saúde pelas PICS e a já existente regulamentação dessas práticas pelo Ministério da Saúde e pela Organização Mundial da Saúde, faz-se necessário maior investimento na formação específica do recurso humano da saúde pelas academias, bem como, o aumento das produções científicas da área. Ressalta-se, na mesma proporção, a importância de se conhecer o que as ações do Projeto de Extensão "Práticas Integrativas Complementares em Saúde: Acupuntura em Odontologia" na Faculdade de Odontologia da UFMG, representam para a formação acadêmica e pessoal dos discentes nele envolvidos.

\section{Referências}

Boscaine, E. de F., Pontes, E. R. J. C., Castillo, D. B., Suliano, L. da S. C., \& Filho, N. T. O. (2019). Acupuntura no tratamento da disfunção temporomandibular muscular. Sociedade Brasileira para o Estudo da Dor. 2(4) 348-355.

Branco, C. A. et al (2005). Acupuntura como tratamento complementar nas disfunções temporomandibulares: revisão de literatura. Revista de Odontologia da UNESP. 34(1) 11-6. 
Brasil. Glossário temático: práticas integrativas e complementares em saúde. Ministério da Saúde. 180 p.

Brasil. Ministério da Saúde. Política Nacional de Práticas Integrativas e Complementares no SUS. Ministério da Saúde, 2015. 98 p.

Brasil. Resolução CFO - 160/2015 DE 02 De Outubro De 2015.Reconhece a Acupuntura, a Homeopatia e a Odontologia do Esporte como especialidades odontológicas.

Chagas, K. E., Melo, C. do V. A., Rocha, I. R., Almeida-Leite, C. M., \& Paula, J. S. (2021). Conhecimento e uso das Práticas Integrativas e Complementares em Saúde por pacientes com dor orofacial. Sociedade Brasileira para o Estudo da Dor. 4(1) 15-19.

Cintra, M. E. R., \& Figueiredo, R. (2010). Acupuntura e promoção de saúde: possibilidades no serviço público de saúde. Comunicação, Saúde, Educação. 14(32) 139-154.

Ferreira, L. A. et al (2015). Ear Acupuncture Therapy for Masticatory Myofascial and Temporomandibular Pain: A Controlled Clinical Trial. Evidence-based Complementary and Alternative Medicine. v.2015, article ID: 342507.

Florian, M. R. et al (2012). Use of acupunture in a case of paresthesia of the left lower alveolar nerve. Revista da Associação Paulista de Cirurgiões Dentistas. 66(4) 312-315.

Garbelotti, T. O. et al (2016). Effectiveness of acupuncture for temporomandibular disorders and associated symptoms. Revista Dor. São Paulo, 17(3) 223227.

Gomes, A. M. de A., Paiva, E. S., Valdés, M. T. M., Frota, M. A., \& Albuquerque, C. de M. (2008). Fenomenologia, Humanização e Promoção da Saúde: uma proposta de articulação. Saúde e Sociedade. 17(1) 143-152.

Lyra, C. S., Nakay, L. S., \& Marques, A. P. (2010). Eficácia da aromaterapia na redução de níveis de estresse e ansiedade em alunos de graduação da área da saúde: estudo preliminar. Revista Fisioterapia e Pesquisa. São Paulo, 17(1).

Minayo, M. C. S. Análise qualitative: teoria, passos e fidedignidade (2012). Cienc Saúde Colet. 17(3) 621-626.

Moura, C. C. et al (2018). Cupping therapy and chronic back pain: systematic review and metaanalysis. Revista Latino-Americana de Enfermagem. 26 , e.3094.

Rando-Meirelles, M. P., Gonçalo, C. S., \& Sousa, M. L. R (2009). Manejo da dor orofacial através do tratamento com acupuntura. Revista de Odontologia da UNESP. 38(6) 379-82.

Santos, D. R., Sperotto, D. F., \& Pinheiro, U. M. S. (2011). A Medicina Tradicional Chinesa no Tratamento do Transtorno de Ansiedade: Um Olhar Sobre o Stress. Contexto \& Saúde, 10(20) 103-112.

Sassi, F. C., Silva, A. P., Santos, R. K. S., \& Andrade, C. R. F. (2018). Tratamento para disfunções temporomandibulares: uma revisão sistemática. Audiology Communication Research. 23:e1871.

Takiguchi, R. S., Fukuhara, V. S., Sauer, J. F., Assumpção, A., \& Marques, A. P. (2008). Efeito da Acupuntura na melhora da dor, sono e qualidade de vida em pacientes fibromiálgicos: estudo preliminar. Revista Fisioterapia e Pesquisa. 15(3).

TRAD LAB. Grupos focais: conceitos, procedimentos e reflexões baseadas em experiências com o uso da técnica em pesquisas de saúde. Physis Revista de Saúde Coletiva, 19(3): 777-796, 2009.

Vasconcelos, F. H. P et al (2011). Acupuntura em odontologia: uma revisão de literatura. Revista Brasileira Ciências da Saúde 9(28) 38-42.

Vera, R. M. De La T., et al (2013). Acupuncture to manage orofacial pain and tinnitus. Case report. Revista Dor. 14(6) 226-330.

Vianna, R. dos S., Granthon, A. de S., Silvia, B. C., Berlinck, T. Á., \& Dias, K. R. H. C. (2008). A Acupuntura e sua aplicação na Odontologia. UFES Revista de Odontologia, 10(4) 48-52.

Wang, Y. T., et al (2017). The effect of cupping therapy for low back pain: A meta-analysis based on existing randomized controlled trials. Journal of Back and Musculoskeletal Rehabilitation. 30(6) 1187-1195.

World Health Organization. WHO traditional medicine strategy: 2014-2023. WHO.

Wirth, D. P.et al (1993). The effect of complementary healing therapy on postoperative pain after surgical removal of impacted third molar teeth. Complementary Therapies in Medicine. 1(3) 133-138.

Zhang, Y., Leach, M. J., Hall, H., Sundberg, T., Ward, L., Sibbritt, D., \& Adams, J. (2015). Differences between male and female consumers of complementary and alternative medicine in a National US Population: a secondary analysis of 2012 NIHS Data. Evid Based Complement Alternat Med. 2015:413173 